\title{
Application and Research of Triaxial Rheological Test System
}

\author{
ZhangDaode $^{1}$, SongChenglong ${ }^{2}$ and YinYang ${ }^{3}$ \\ 1, 2, ${ }^{3}$ School of Mechanical Engineering, Hubei University of Technology, Wuhan, \\ 430068, China \\ 1hgzdd@126.com,2scl80h@163.com,3472142702@qq.com
}

\begin{abstract}
To research rheological characteristics of rock under the High-stress Zone of Deep Deposit and unloading etc, complex stress condition, development of triaxial rheological test system. This system uses Fuji GYS401D5-RC2 servo system, configuration Advantech's PCI-1240U motion control card and PCI-1716 data acquisition card, using PID control algorithm to achieve a constant voltage, constant speed and constant displacement pump control. Tests show that the system automatically regulated, data acquisition etc, the whole performance meets the experimental demand of triaxial rheological test system.
\end{abstract}

Key words: Triaxial rheological test system, Servo system, Data acquisition, PID

\section{Introduction}

Triaxial rheological test system is mainly used to develop rock material rheological tests under stress, temperature, flow, chemical corrosion coupling conditions. With the process of economic modernization, improvement of infrastructure, engineering and construction flourished, the application of new materials, frequent occurrences of geological disasters, advocating environmental protection. Triaxial rheological test system has been widely used in geotechnical engineering, construction materials, research and application of geological disasters and other fields, especially in the field of geotechnical engineering, triaxial rheological test system undertakes the slope stability, tunnel surrounding rock maintenance, rock burst, seismic effect and the heavy task of research and engineering applications of other aspects[1].

Because of the deep underground rock in complex stress state, but rock itself is a very complex natural materials, rock creep test under the simple stress state may not fully reflect the actual engineering rock behavior, due to its complexity and diversity, the rheological properties of rocks still exist a number of problems to be solved, one of the key technologies is how to use a reliable test equipment and test techniques to obtain reliable rheological test measured curve and data.

The rheological test is an important means to study the rheological mechanical properties of rock, the test results are the basis of rheological constitutive model study, since laboratory tests have long-term observation, can be strictly controlled test conditions, more repetitions and less cost etc, has been widely appreciated.

\section{System General Scheme}

\subsection{The Overall Framework}

Triaxial rheological test system can be studied confining pressure, pore pressure, load time and temperature effects on rock traits, softening effect of various fluids and Permeability rocks. These experiments are based on the change of shape and the volume, the internal pressure change and the change of the size of the force in the sample surface. 
The experiment needs to be done a certain size rock samples processed into a cylindrical sample, placed in the rubber sleeve, fixed on the test bench, from sensor to collect a variety of data, after signal conditioning, data collected by the data acquisition card. Data collected through effective analysis, after the set value, the use of PID algorithm, using NI's LabVIEW programming. Using motion control card to control the servo motor effective campaign, servo motor driven ball screw to convert rotary motion into linear motion, push pump produces pressure, that loaded into the steel cylinder surrounding the sample through a metal pipe. Thereby providing an effective axial pressure, confining pressure and pore pressure for sample, that simulate real life situations Geotechnical Material is subjected to a vertical stress, the side of compressive stress and infiltration of groundwater. The program uses a closed-loop control, to complete a variety of experimental rock and soil materials [2].

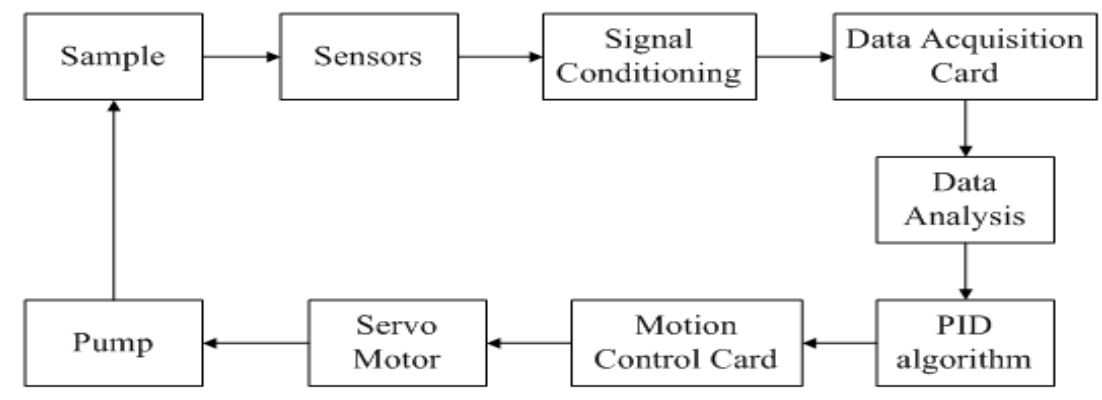

Figure 1. The System Structure

\subsection{The System Uses}

Triaxial rheological test system can be used to study the following experimental such as rock, concrete and other materials [3]:

(1) Long-term creep test at room temperature

Under uniaxial or triaxial stress state, various samples were drained or undrained creep, expansion - the destruction experiments. Obtain the stress - strain - time relationships and other mechanical parameters with time-related.

(2)Conventional experiments (not study time effect)

Under uniaxial or triaxial stress state, various samples were drained triaxial compression test or orundrainedtriaxial compression experiments. Measured the stress strain curves, determine various deformation modulus and strength index.

(3) Under different stress, temperature, and pore water pressure conditions, the material uniaxial or triaxial creep expansion - the destruction experiments. Establish its constitutive determine its relevant parameters, which helps to study the stability of the oil, nuclear waste repository, rock, rock salt and other projects for engineering design, construction or reinforcement to take effective measures to provide experimental and theoretical basis.

(4) Other experiments

In rock mechanics, these tests would contribute to research the effectiveness of project safety measures such as reservoir earthquake mechanism, rock burst and underground tunnel, and nuclear waste repository and deep wells for safe use and reinforcement measures to provide test data.

\section{Hardware Structure}

Triaxial rheological test system is mainly composed of pressure pump, servo motors, motion control card, data acquisition card, pressing metal pipes, vertical jacks and triaxialchamber [4]. It provides which for the sample long-term constant axial pressure, confining pressure, pore pressure and constant displacement. 


\subsection{Loading System}

Servo motor controlled by motion control card, and hydraulic pumps output three pressure, which axial pressure and confining pressure provided by the oil pressure, pore pressure provided by the water pressure. Axial pressure oil enters the high stiffness load host though metal pipes. Confining pressure oil enters the chamber through the holes in the base. Pore pressure water through the base center enters the bottom of the sample [5].

Among them, three sets of Fuji GYS401D5-RC2 servo systems are controlled by Advantech's PCI-1240U motion control card. Shaft pump, confining pressure pump and pore pressure pump, respectively, combined with axial pressure servo system, confining pressure servo system and pore pressure servo system, respectively, providing axial pressure, confining pressure and pore pressure to rock samples, which to meet the experimental requirements under constant pressure and constant displacement conditions [6].

\subsection{Triaxial Chamber}

Triaxial chamber fixed chamber cap, steel barrel and base together by means of screw, this design is simple structure, small size, easy to operate [7].

There are two axial displacement sensors and a circumferential displacement sensor into triaxial chamber connected with Advantech's PCI-1716 data acquisition card, the purpose is real-time recording rheological displacement in the course of the rheological, and can be a constant axial displacement control [8]. Around triaxial chamber, the pressure sensor is connected to the data acquisition card, the purpose is real-time recording axial pressure, confining pressure and pore pressure which in the rheological testing process, and can achieve three pumps with a constant rate or constant voltage control simultaneously. Into the chamber, thermocouple is connected to the data acquisition card, the real-time temperature data acquisition in the rheological process. A full-bridge and Four quarter-bridge strain gauges are fixed by the side of the rock sample to collect real-axial deformation and lateral deformation of rock samples under rheological process.

Triaxial rheological test system diagram is shown in Figure 2.

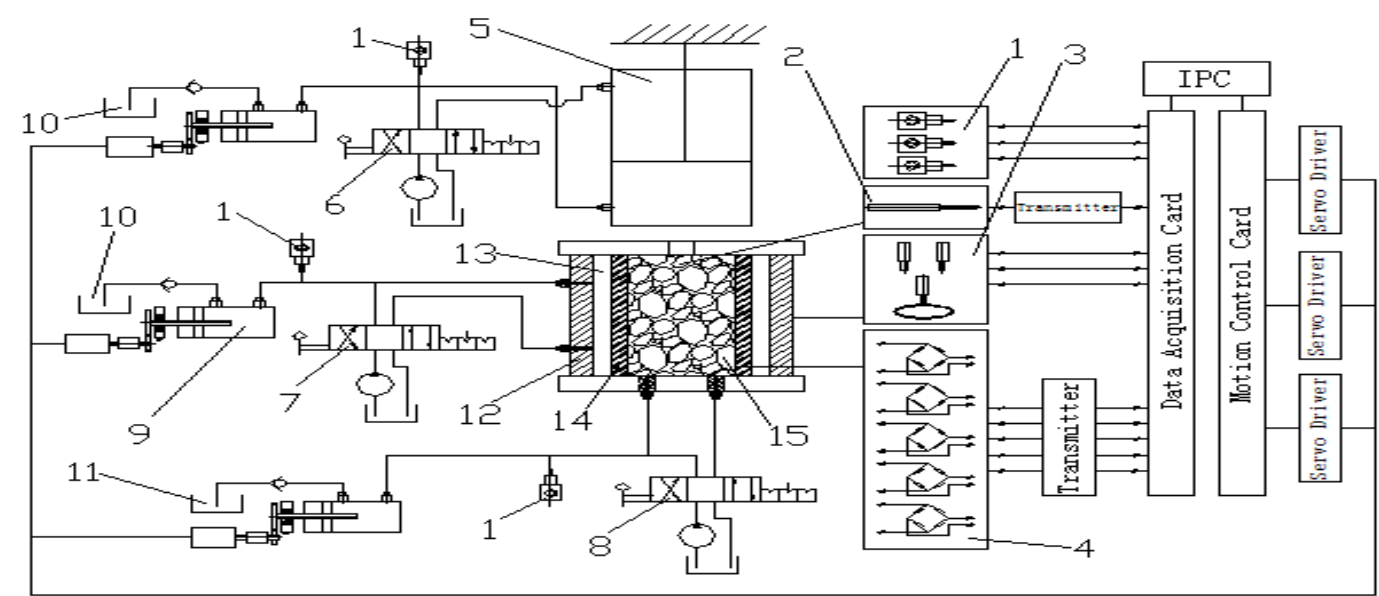

1. Pressure Transmitter 2.Thermocouple 3. Displacement Sensor

4. Full-Bridge and $1 / 4$ Bridge strain gauge 5. Axis Pressure Cylinder

6. Axis Pressure Manual Valve 7. Confining Pressure Manual Valve

8. Pore pressure Manual Valve 9.Servo Motor 10.Hydraulic Oil 11.Water

12. Steel Tube 13. Hydraulic Oil 14.Rubber Sleeve 15.rock samples

Figure 2. Triaxial Rheological Test System Control System Schematic 


\section{System Software Design}

\subsection{Software Structure}

Triaxial rheological test system is mainly divided into parameter setting, data acquisition, motion control, data saved four parts. Which part of the data acquisition and motion control by calling the dynamic link library approach, using LabVIEW programming can be very easy to achieve [9]. For constant pressure and constant displacement of the three axes need to use PID control algorithm. Specific software structure is shown in Figure 3.

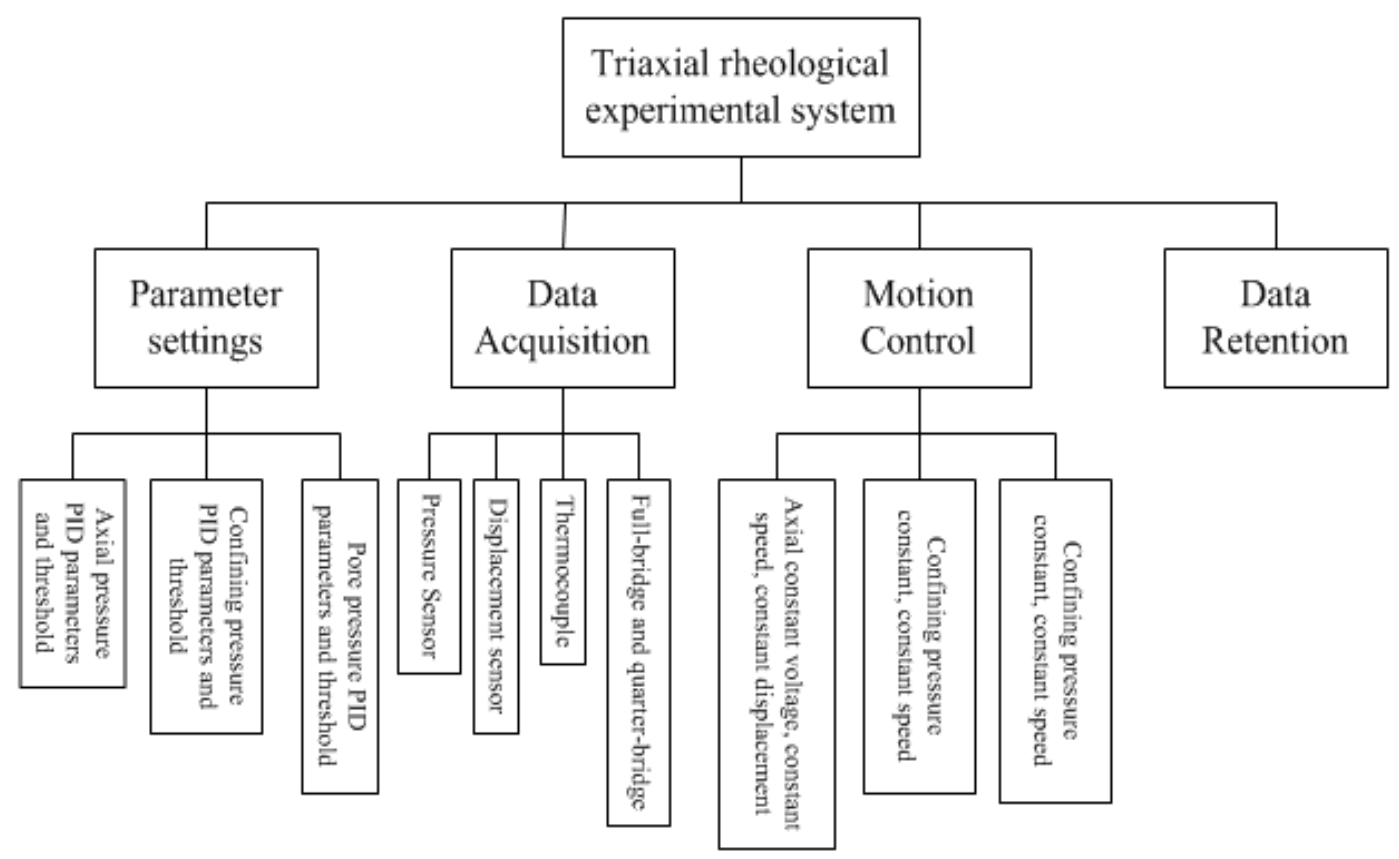

Figure 3. Software Structure

\subsection{Software Implementation}

In the conventional PID control, the introduction of the integral part of the purpose is mainly to eliminate static error and improve control accuracy. But in the process of starting and ending or significantly change settings, system output will have a great deviation in a short time, which can cause integral accumulation in PID operation, resulting amount of control over executive agencies may allow a maximum operating range corresponds to the amount of the limit control, which cause the system to a large overshoot, or even cause the system to a large oscillation, this is in high demand in the system is absolutely not allowed. Introduction of integral separation PID control algorithm, while maintaining the role of integration, but also reduces the overshoot, so that the control performance has been greatly improved.

The control Fundamentals of integral separation is that when the controlled variable and settings has a larger deviation, canceled integral action, so as to avoid the integral action to reduce the system stability, overshoot increases[10].

When the controlled variable is close to a given value, the introduction of integral control, in order to eliminate the static error, and improve the control accuracy[11].

Triaxial rheological test system uses similar integral separation PID control algorithm, and achieve the following specific:

(1)According to actual situation, set the integral separation threshold $\varepsilon>0$;

(2)At that time $|\mathrm{e}(\mathrm{k})|>\varepsilon$, PD control, the system has a fast response; 
(3)At that time $|\mathrm{e}(\mathrm{k})| \leq \varepsilon$, PID control to ensure the accuracy of the control system.

The control algorithm of PID diagram as follows:

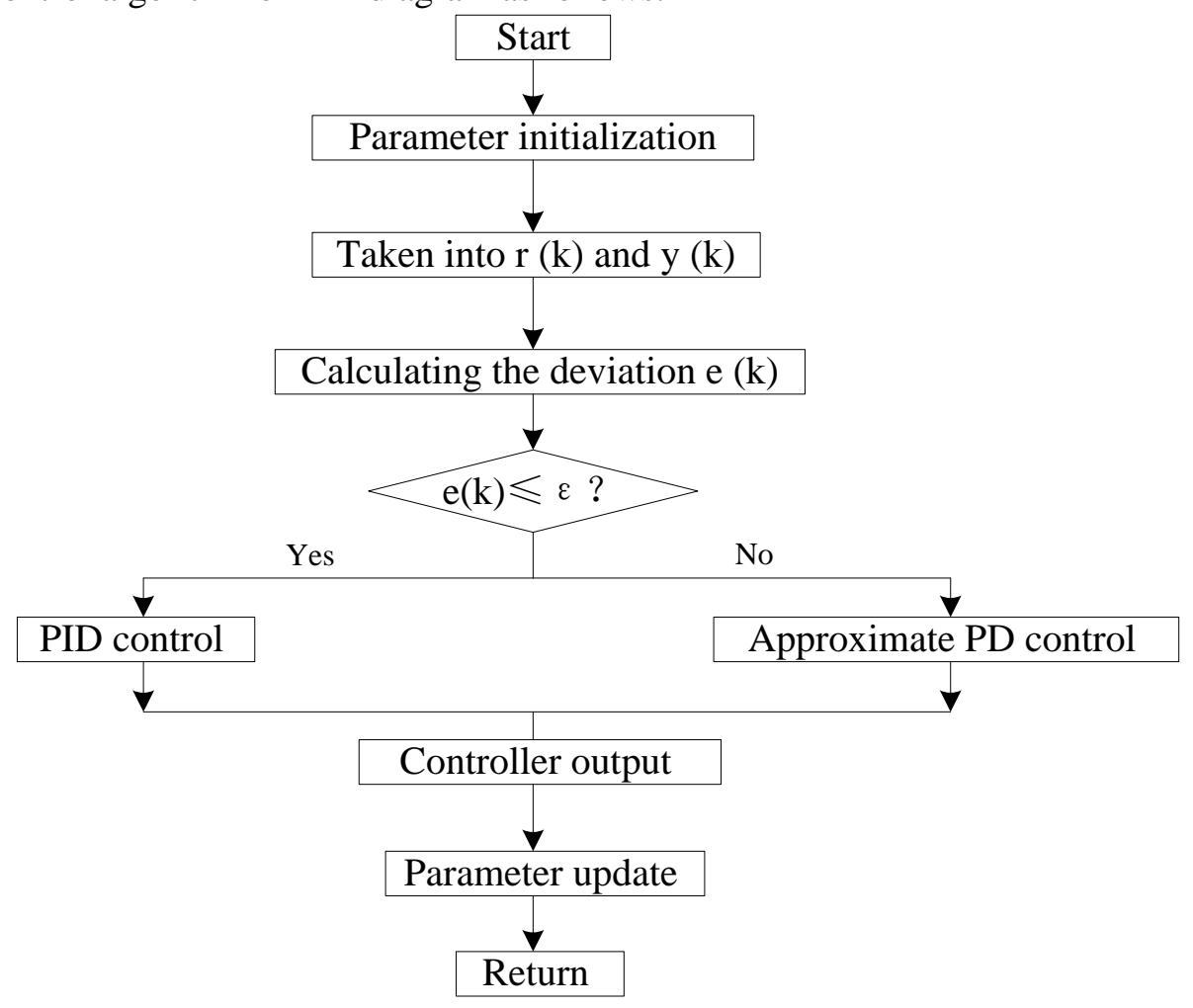

Figure 4. PID Control Algorithm Block Diagram

Expression of PID control algorithm is as follows:

$r(t)$ is the given value, $y(t)$ is the actual output value of the system, the setpoint and the actual output value constitute control deviation $\mathrm{e}(\mathrm{t})$, the expression of $\mathrm{e}(\mathrm{t})$ is as follows:

$$
e(t)=r(t)-y(t)
$$

Expression of conventional analog PID control algorithm:

$$
\begin{aligned}
u(t) & =K_{p}\left[e(t)+\frac{1}{T_{i}} \int_{0}^{t} e(t) d t+T_{d} \frac{d e(t)}{d t}\right] \\
& =K_{p} e(t)+\frac{K_{p}}{T_{i}} \int_{0}^{t} e(t) d t+K_{p} T_{d} \frac{d e(t)}{d t}
\end{aligned}
$$

Formula (1) discretization, discrete sampling time kT corresponds to a continuous time t, the rectangular numerical integration method approximation instead of integral and one step backward difference approximation instead of the differential which can be approximated as follows transformations:

$$
\begin{gathered}
\mathrm{t} \approx \mathrm{kT} \quad(\mathrm{k}=0,1,2 \ldots \ldots) \\
\int_{0}^{\mathrm{t}} \mathrm{e}(\mathrm{t}) \mathrm{dt} \approx \mathrm{T} \sum_{\mathrm{j}=0}^{\mathrm{k}} \mathrm{e}(\mathrm{jT}) \\
\frac{\mathrm{de}(\mathrm{t})}{\mathrm{dt}} \approx \frac{\mathrm{e}(\mathrm{kT})-\mathrm{e}[(\mathrm{k}-1) \mathrm{T}]}{\mathrm{T}}
\end{gathered}
$$

After sampling the formula (1) can be changed to:

$$
\mathrm{u}(\mathrm{k})=\mathrm{K}_{\mathrm{p}}\left\{\mathrm{e}(\mathrm{k})+\frac{\mathrm{T}}{\mathrm{T}_{\mathrm{i}}} \sum_{\mathrm{j}=0}^{\mathrm{k}} \mathrm{e}(\mathrm{j})+\frac{\mathrm{T}_{\mathrm{d}}}{\mathrm{T}}[\mathrm{e}(\mathrm{k})-\mathrm{e}(\mathrm{k}-1)]\right\}
$$




$$
=K_{p} e(k)+\frac{K_{p} T}{T_{i}} \sum_{j=0}^{k} e(j)+\frac{K_{p} T_{d}}{T}[e(k)-e(k-1)]
$$

According to formula (2) can be the expression of $\mathrm{u}(\mathrm{k}-1)$, that is,

$$
\mathrm{u}(\mathrm{k}-1)=\mathrm{K}_{\mathrm{p}} \mathrm{e}(\mathrm{k}-1)+\frac{\mathrm{K}_{\mathrm{p}} \mathrm{T}}{\mathrm{T}_{\mathrm{i}}} \sum_{\mathrm{j}=1}^{\mathrm{k}-1} \mathrm{e}(\mathrm{j})+\frac{\mathrm{K}_{\mathrm{p}} \mathrm{T}_{\mathrm{d}}}{\mathrm{T}}[\mathrm{e}(\mathrm{k}-1)-\mathrm{e}(\mathrm{k}-2)]
$$

Formula (2) minus formula (3), that was the expression of incremental digital PID control:

Formula (4) can be transformed into

$$
\begin{aligned}
\Delta \mathrm{u}(\mathrm{k})=\mathrm{K}_{\mathrm{p}}[\mathrm{e}(\mathrm{k}) & -\mathrm{e}(\mathrm{k}-1)]+\mathrm{K}_{\mathrm{p}} \frac{\mathrm{T}}{\mathrm{T}_{\mathrm{i}}} \mathrm{e}(\mathrm{k}) \\
& +\mathrm{K}_{\mathrm{p}} \frac{\mathrm{T}_{\mathrm{d}}}{\mathrm{T}}[\mathrm{e}(\mathrm{k})-2 \mathrm{e}(\mathrm{k}-1)+\mathrm{e}(\mathrm{k}-2)]
\end{aligned}
$$

$$
\begin{aligned}
\Delta \mathrm{u}(\mathrm{k})=\mathrm{Ae}(\mathrm{k}) & -\mathrm{Be}(\mathrm{k}-1) \\
+ & \mathrm{Ce}(\mathrm{k}-2)
\end{aligned}
$$

Among them,

$$
\begin{array}{r}
A=K_{p}\left(1+\frac{T}{T_{i}}+\frac{T_{d}}{T}\right) \\
B=K_{p}\left(1+\frac{2 T_{d}}{T}\right) \\
C=K_{p} \frac{T_{d}}{T}
\end{array}
$$

Using LabVIEW provides a powerful graphical programming software development tools, you can easily achieve the desired function[12]. Figure 5, Figure 6 is a block diagram with LabVIEW VI of the PID control algorithm.

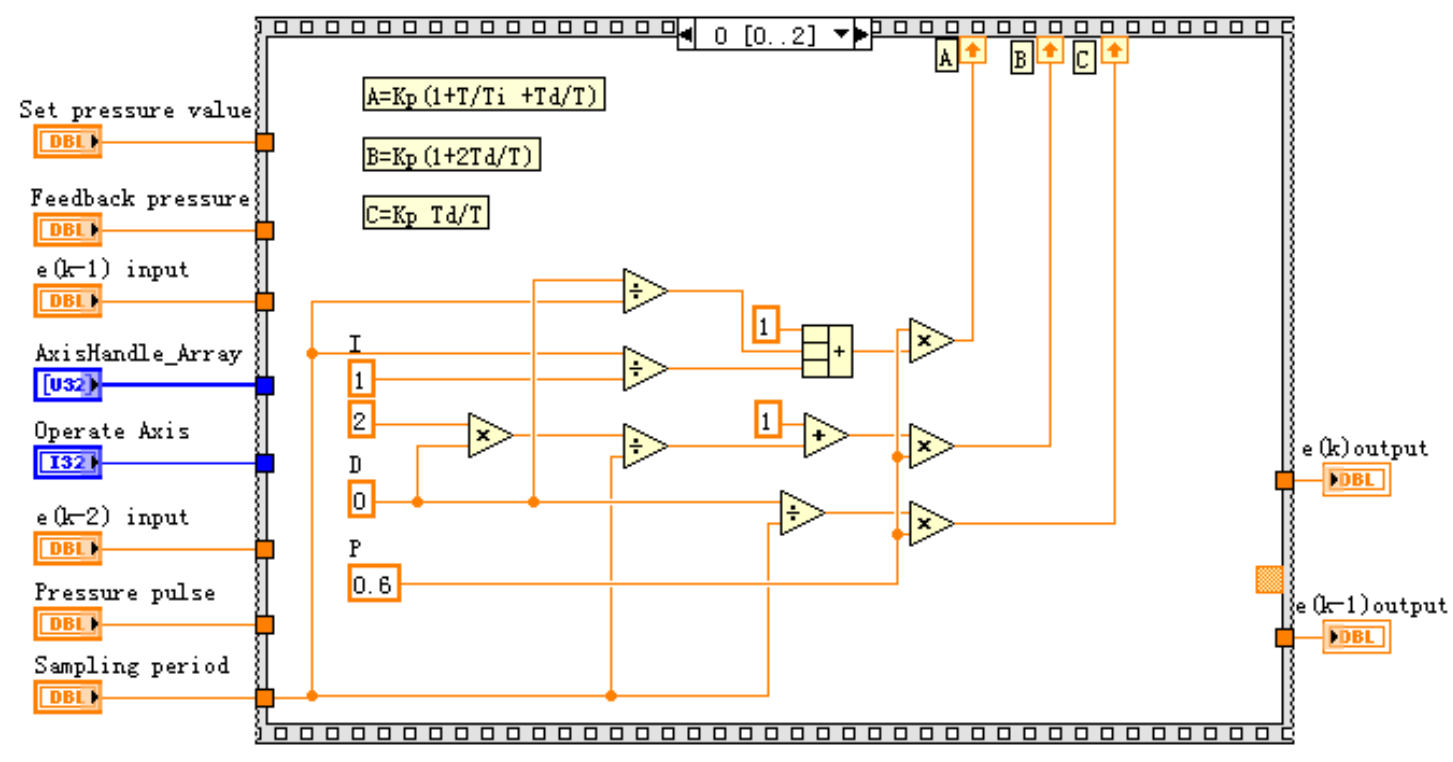

Figure 5. PID Part of the Block Diagram 


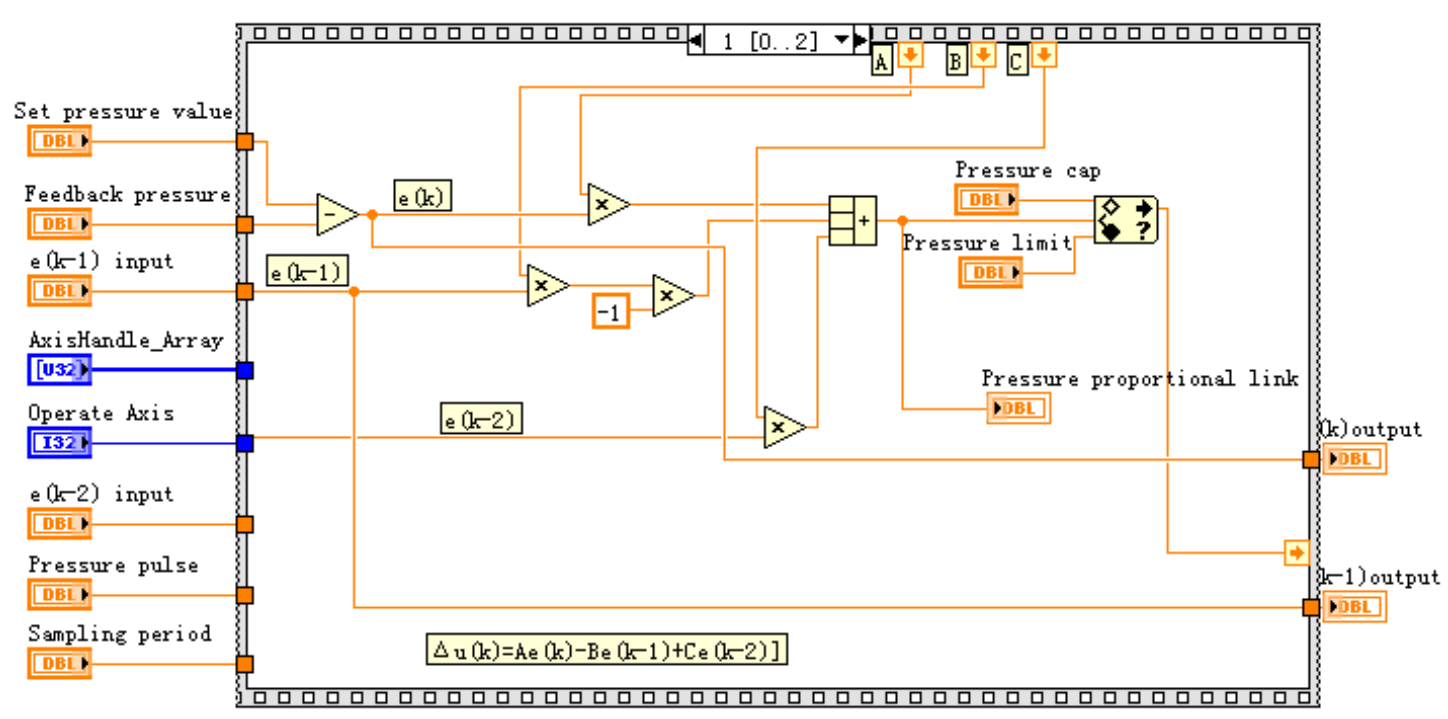

Figure 6. PID Part of the Block Diagram

\section{The Test Results and Discussion}

Final triaxial rheological test system achieve the control of pump with constant voltage, constant speed and constant displacement, the test shows that the whole performance of the system of automatic voltage regulator, such as data collection, meet the experiment demand three rock rheological test system. Softwareinterface is shown in Figure 7.

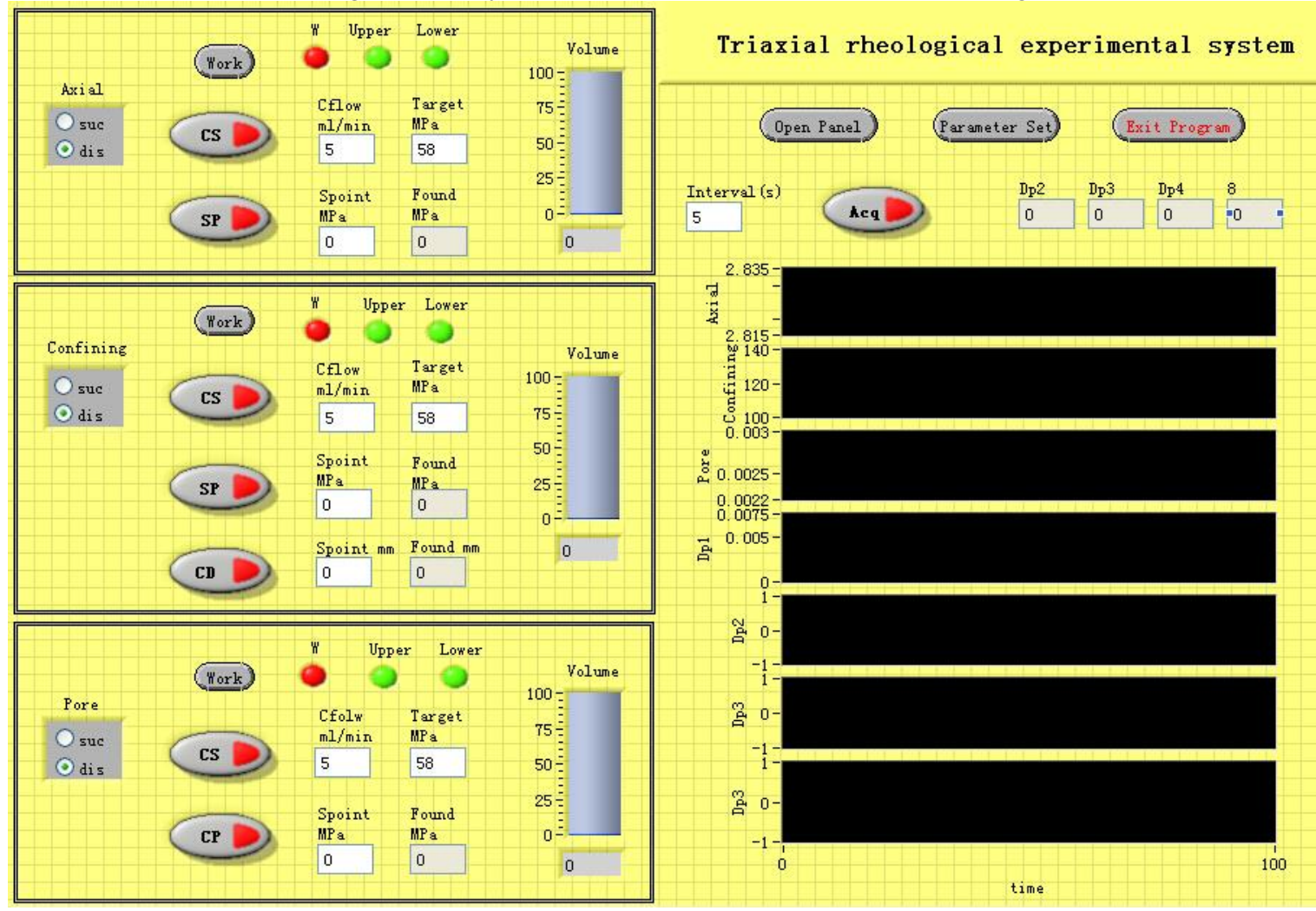

Figure 7. Software Interface 
By constantly testing, adjust the PID parameter settings, set the parameters as follows:

\begin{tabular}{|c|c|c|c|c|c|}
\hline Parameter name & P1 & I1 & D1 & Rate 1 (PPU/S) & Sampling period (s) \\
\hline Value & 0.6 & 1 & 0 & 1500 & 0.5 \\
\hline Parameter name & P2 & I2 & D2 & Rate 2 (PPU/S) & Threshold (MPa) \\
\hline Value & 0.6 & 15 & 0 & 40 & 0.03 \\
\hline
\end{tabular}

The maximum range of three pumps are 60MPa, When the axial pressure pump is set to a constant pressure to $15 \mathrm{MPa}$, the confining pressure pump is set to a constant pressure to $5 \mathrm{MPa}$, and the pore pressure pump is set to a constant pressure to $2 \mathrm{MPa}$, the waveforms can be obtained as follows:

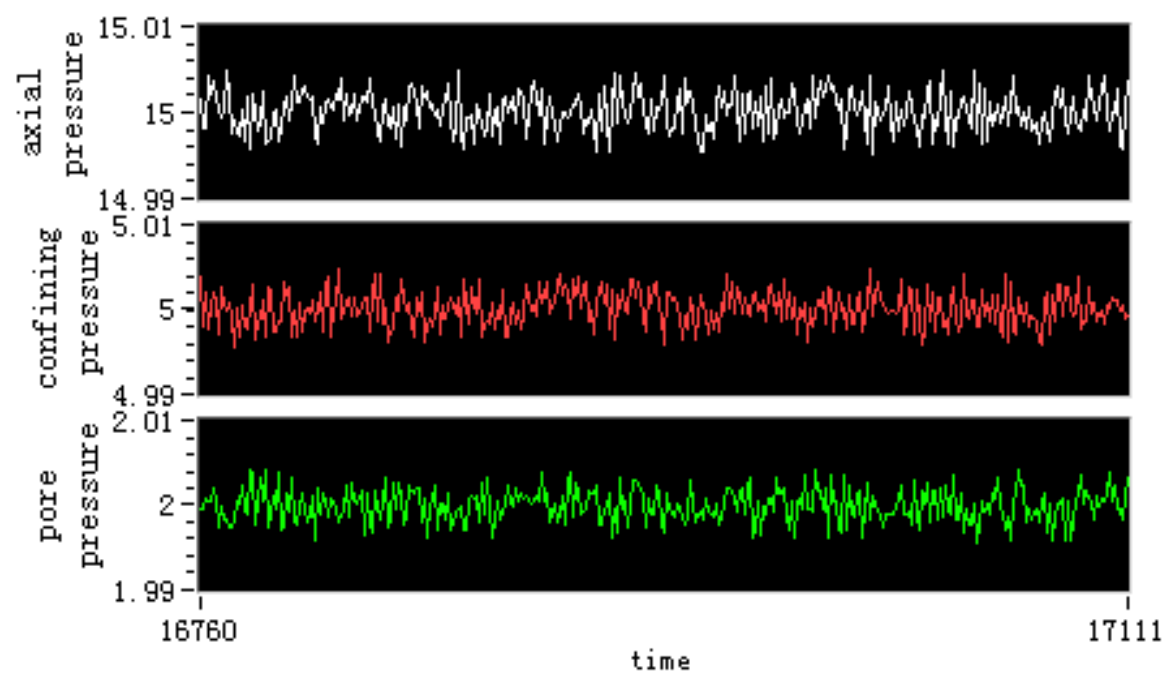

Figure 8. Constant Displacement

Axial displacement sensor maximum range of $10 \mathrm{~mm}$, when setting the displacement of axial pressure pump is $1.655 \mathrm{~mm}$, the waveforms can be obtained as follows:

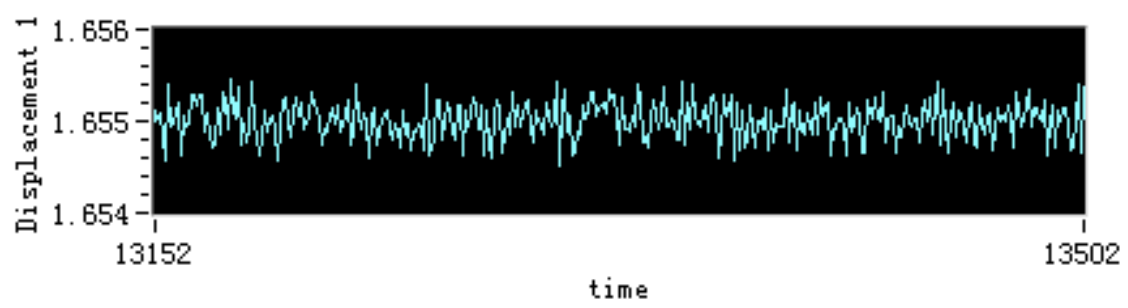

Figure 9. Constant Pressure

Experiment shown that triaxial rheological test system can be very fast response, not only meet the accuracy requirements of the constant pressure $0.01 \mathrm{MPa}$, but also meet the accuracy requirements of the constant displacement $0.001 \mathrm{~mm}$ which in the axial direction. Through a long period of testing, the control system is very stable, good accuracy can meet the needs of the experiment.

\section{Conclusion}

Triaxial rheological test system has good performance of constant pressure. The whole process of testing automatic acquisition, automatic recording, automatically saved and automatic drawing deformation versus time curve, etc. The test system has a high precision in triaxial creep experimentation, which could provide in-depth study of the 
rheological properties of rock under high stress conditions, solving the problem of underground caverns and rocky slope which under complex conditions which has longterm deformation and long-term stability, and provide support for the theory and practice[13].

The triaxial rheological test system for the study of Chinese soft rock deep underground engineering (water conservancy, mining, petroleum, nuclear waste reservoir) rheological properties provide a new test platform, we can see that the device is not only an important rheological test the value of research, but also has a very bright future practical application, the promotion of high value.

\section{Acknowledgements}

This work is supported by Natural Science Foundation of Hubei Province (No.2014CFA528).

\section{References}

[1] H. M. Zhou and Q. Z. Hao,"RLW-2000Triaxial rheological test system development”, Mine pressure and roof management, vol.31, no.3, (2005), pp.55-57.

[2] C. Kan and X. D. Kong, "Identification of the material testing machine model servo pressure control system”, China Mechanical Engineering, vol.18, no.1, (2007), pp.907-911.

[3] W. F. Kang, "Multipurpose Rock Triaxial Rheological Apparatus and Its Application in Rock Mechanics", Chinese Journal of Rock Mechanics and Engineering, vol.8, no.1, (1989), pp.37-51.

[4] W. G. Wang, "Development of an automatic hydraulic pressure control systemtest", Chinese Hydraulics \& Pneumatics, vol.34, no.12, (2010), pp.35-38.

[5] M. Z. Cao and L. Quan, "Research on Variable speed pump control system is applied to low-cycle fatigue testing machine", Journal of Taiyuan University of Technology, vol.37, no.1, (2006), pp.5-8.

[6] D. J, "On Multi-function Digital Control System", Journal of Chongqing University of Science and Technology (Natural Sciences Edition), vol.8, no.4, (2006), pp.61-71.

[7] G. C. Bai, Z. L. Wang and X. Y. Qi, "Aviation hydraulic variable load Accelerated Life Test Stand", Chinese Hydraulics \& Pneumatics, vol.30, no.3, (2006), pp.47-50.

[8] M. Yang and J. H. Zhou, "Based on the design of control card to the material testing machine system", Mechanical Engineering \& Automation, vol.41, no.1, (2012), pp.124-126.

[9] G. T. Li, R. X. Li and J. F. Kang, "Based on Virtual Instrument Technology Measurement and Control System Hydraulic Pump", Transactions of the Chinese Society for Agricultural Machinery, vol.36, no.12, (2005), pp.121-137.

[10] A. Li, "Integral Separation PID control algorithm in PLC temperature control system", Electronic Design Engineering, vol.21, no.24, (2013), pp.54-58.

[11] J. L. Xu and C. Chen, "Application of heat treatment resistance furnace fuzzy control”, Hot Working Technology, vol.43, no.5, (2002), pp.58-59.

[12] J. Gao, "Based on LabVIEW graphical programming to the PID control algorithm", Software Guide, vol.11, no.4, (2012), pp.51-53.

[13] Q. Chen, K. Nishida, T. Iwamoto, H. Kameya and T. Itabasi, "Creep behavior of sedimentary soft rock under triaxial compression”, Chinese Journal of Rock Mechanics and Engineering, vol.22, no.6, (2003), pp.905-912.

\section{Authors}

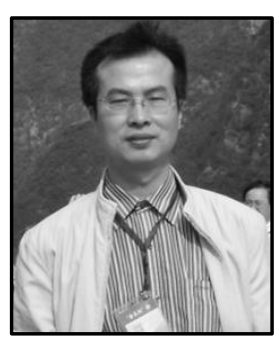

Zhang Daode, he received the $\mathrm{PhD}$ degree from Huazhong University of Science and Technology.Now, he is a professor in the School of Mechanical Engineering, Hubei University of Technology.His research interests are in FPGA, signal processing and robot control. 


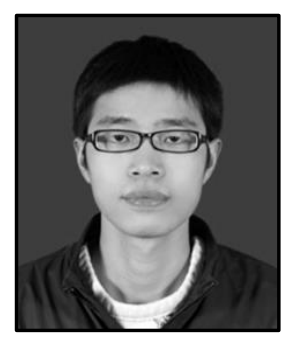

Song Chenglong, he recieved bachelor degree in theSchool of Mechanical Engineering, Hubei University of Technology in 2008.Now studying in Hubei University of Technology as a master. His majority interests include artificial intelligence, motion controland FPGA.

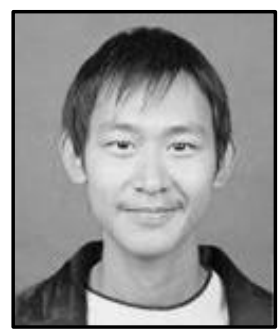

YinYang, he graduated from theWenHua Collegein 2008. Now studying in Hubei University of Technology as a master. His majority interests include artificial intelligence, FPGA and robot control. 